\title{
Federico Albert: apreciaciones sobre la caza y pesca de los lobos marinos en los territorios australes de Chile, $1901^{1}$
}

\author{
Federico Albert: appreciations about seal hunting \\ and fishing in the austral territories of Chile, 1901 \\ Pablo Mancilla González \\ "Profesor de Historia y Geografía y Magister en Historia \\ Académico Asociado Universidad Santo Tomás, Viña del Mar, Chile \\ $\measuredangle$ pmancillag@santotomas.cl
}

\begin{abstract}
RESUMEN
El trabajo analiza los aportes de Federico Albert a la discusión sobre los beneficios y perjuicios de la Ordenanza de Pesca $\mathrm{N}^{0} 1.623$ que reguló la explotación de los lobos marinos en los mares y costas de Chile entre 1892 y 1904 a través de dos de sus trabajos: "Los lobos marinos de Chile" y "Los pinípedos de Chile", publicados en 1901 en la Revista Chilena de Historia Natural del Museo de Historia Natural de Valparaíso y en Anales de la Universidad de Chile, respectivamente. Se concluye que, como científico y funcionario público, Albert fue fundamental para buscar nuevas alternativas para proteger a estos mamíferos marinos a principios del siglo XX.
\end{abstract}

PALABRAS CLAVE: Federico Albert, Pesca y caza de lobos marinos, Ordenanza de Pesca No 1.623 de 1892.

\section{ABSTRACT}

This paper analyzes the contributions of Federico Albert to the discussion about the benefits and prejudices of the Fishing Regulation $\mathrm{N}^{0} 1.623$ that ruled the sealing industry in the seas and coasts of Chile between 1892 and 1904 through two works: "The seals in Chile" and "The pinnipeds of Chile", published in 1901 in the Chilean Journal of Natural History of the Natural History Museum of Valparaíso and in the Annals of University of Chile,

1 Proyecto Conicyt-Fondecyt Regular No 1170314, titulado “El Piloto 2 Luis Pardo Villalón y la Segunda Carta Patente Británica: La Política Antártica Chilena entre la Pertenencia Histórica y la Incertidumbre Internacional, 1906-1917". 
respectively. It is concluded that, as a scientist and civil servant, Albert was essential to look for new alternatives to protect these sea mammals at the beginning of the XX Century.

KEY WORDS: Federico Albert, Fur-Seal hunting and fishing, Fishing Regulation No 1.623 of 1892 .

\section{INTRODUCCIÓN}

Federico Albert, nació en Berlín en noviembre 1867 y realizó sus primeros estudios en el Real Gimnasio de Dorotea de la misma ciudad. Entre 1885 y 1887, estudió en la Universidad de Munich donde obtuvo el Bachillerato en Botánica y el Doctorado en Ciencias Naturales, perfeccionándose en las áreas de microscopía, embriología, anatomía e histología animal y vegetal (Yáñez \& Canto, 2013).

En 1888, mientras trabajaba en el Jardín Botánico de Berlín, fue contactado por Domingo Gana Cruz con el ofrecimiento de viajar a Chile para asumir como profesor en el Instituto Pedagógico y preparador del Museo Nacional de Historia Natural. Un año después, viajó a Chile e inmediatamente se puso a las órdenes de Rodolfo Philippi, director del Museo, con quien trabajo por casi una década realizando investigaciones de gabinete, viajes de exploración y recopilaciones de muestras animales y vegetales para el Museo.

En 1898, se trasladó al Ministerio de Industria y Obras Públicas y, en 1900, fue nombrado director de la Sección de Ensayos Zoológicos y Botánicos, donde destacó por sus investigaciones, publicaciones, conferencias y propuestas para la elaboración de leyes, reglamentos y ordenanzas para la regulación y resguardo de los recursos naturales del país, siendo muchas de ellas criticadas por políticos, empresarios e industriales que vieron en él y su trabajo un verdadero peligro para el desarrollo de las actividades económicas nacionales, principalmente las vinculadas con la explotación de los recursos forestales y marinos.

A su muerte en noviembre de 1928, Federico Albert había publicado más de cien trabajos sobre temáticas científicas y administrativas, destacando entre sus libros La caza en el país (1902), La replantación de los cerros áridos del país (1906), Los servicios de agua y bosques (1906), Plan general para el cultivo de bosques (1907), Los 7 árboles forestales más recomendables para el país (1909), La organización que se debe dar en lo futuro a los servicios de aguas y bosques de acuerdo a los estudios hechos en Europa (1910), La necesidad urgente de crear una Inspección General de Bosques, Pesca y Caza (1911), El problema pesquero en Chile (1913), Informaciones para establecer un intercambio comercial y fomentar la implantación de industrias y empresas nacionales (1924) y, entre sus artículos, "La langosta de Juan Fernández y la posibilidad de su propagación en la costa chilena” (1898a), “Contribución al estudio de las aves chilenas" (1898b), "Las dunas, o sean las arenas volantes, voladeros, arenas muertas, invasión de las arenas, playas i médanos del centro de Chile" (1900), "Los pinípedos de Chile" (1901a) y "Los lobos marinos de Chile" (1901b). 
Estas publicaciones son consideradas hasta la actualidad de gran valor, especialmente porque a través de ellas se puede comprender el pensamiento de Federico Albert sobre la importancia de elaborar políticas con sustento científico para lograr el debido equilibrio entre la conservación y explotación de los recursos (Camus, 2003).

Sin embargo lo anterior, a pesar de la gran labor que realizó en beneficio de Chile, los escasos estudios que han profundizado sobre su vida y obra se centran preferentemente en su contribución a la defensa de los recursos forestales y los impactos en los avances de las dunas en diversas zonas del país, sin considerar sus aportes a la regulación de la explotación de los recursos marinos, principalmente los lobos marinos. Es así, que el presente trabajo se analizarán los aportes de Federico Albert a la discusión sobre la pesca y caza de lobos marinos en los mares y costas de Chile, especialmente en la zona austral y antártica, regulada por la Ordenanza de Pesca No 1.623 que estuvo vigente entre 1892 y 1904, a través de dos de sus escritos "Los lobos marinos de Chile" y "Los pinípedos de Chile”, publicados en 1901 en la Revista Chilena de Historia Natural del Museo de Historia Natural de Valparaíso y en Anales de la Universidad de Chile, respectivamente.

\section{ESBOZO RELACIONAL ENTRE EL AVANCE DEL CONOCIMIENTO Y LA BÚSQUEDA DE UNA REGULACIÓN DE LA EXPLOTACIÓN DE LOS LOBOS MARINOS EN CHILE, 1750-1901}

Desde mediados del siglo XVII hasta los inicios del siglo XX, se evidencia en las obras consultadas una evolución paulatina sobre el conocimiento que se tuvo en Chile sobre los lobos marinos, principalmente en aspectos vinculados con las diferencias entre especies y géneros, ubicaciones geográficas, períodos de reproducción, costumbres alimentarias, lugares de explotación, técnicas para su pesca, caza y faenamiento, valor comercial en los mercados nacionales y extranjeros de pieles y aceites, entre otros, los que serán utilizados por las autoridades nacionales para elaborar reglamentos que buscaron resguardar su existencia ante la desmesurada explotación en los mares y costas nacionales, especialmente en el archipiélago de Juan Fernández, Chiloé, Magallanes y Tierra del Fuego y las islas australes con proyección al continente antártico (Martinic, 1973; Mayorga, 2016).

Los primeros antecedentes encontrados en la bibliografía sobre la pesca y caza de lobos marinos se remontan al período colonial, donde algunos cronistas que recorrieron las costas e islas nacionales se asombraron por su abundancia y del uso que los aborígenes hacían de sus carnes, aceites y pieles. Un ejemplo de estos relatos es el realizado por el padre Diego de Rosales (1877) en Historia General del Reino de Chile, Flandes Indiano, quien en el capítulo referido a "Las fieras marinas, y de otras bestias que viven en la mar y tierra llamadas animales anfibios o dudosos” (pp. 305-309), realizó comentarios sobre el comportamiento y alimentación y bondadoso número de lobos marinos en toda la costa del país y del comercio iniciado en Lima con sus pieles, las que eran utilizadas para la elaboración de sillas de montar, sombreros, baúles y otros aparejos y adornos de gran valor. 
Durante el siglo XVIII e inicios de la siguiente centuria, la explotación de lobos marinos en los mares y costas de Chile se realizó por embarcaciones provenientes de Norteamérica y Europa, muchas de las cuales, según José Toribio Medina (1952), trataron de entablar conversaciones con las autoridades del país para obtener permisos para su pesca y caza. En ese mismo período, la comunidad científica comenzó a estudiar a los lobos marinos con mayor detenimiento, principalmente por la necesidad de conocer su morfología, determinar su distribución geográfica, definir su densidad poblacional y formas de reproducción y, además, para identificar cuáles eran económicamente más o menos beneficiosas, destacando en estos años los trabajos de M. Joly (1858), Robert Walker (1863), John E. Gray (1863, 1866, 1868 y 1874), Joel Allen (1870) y J. W. Clark (1878).

En Chile, no existen antecedentes fidedignos que ayuden a establecer con exactitud el inicio del estudio científico y económico de los lobos marinos, sin embargo, en las obras de Miguel de Olivares, Juan Ignacio Molina, José Pérez de García y Claudio Gay, ya se evidencia un mayor conocimiento sobre estos aspectos que serán de enorme importancia como antecedentes para las reglamentaciones que, en el futuro, regularán su explotación. En tal sentido, por ejemplo, el jesuita Miguel de Olivares (1864) en la obra Historia militar, civil y sagrada de lo acaecido en la conquista y pacificación del Reino de Chile, específicamente en el capítulo "De las particularidades y abundancia de los peces de Chile”, expuso: "Se pescó en la playa de la Concepción, un cochino marino, semejante en todo al terrestre, menos en la piel que era suave y lisa, y en los pies anteriores y posteriores que tenía acomodados como era preciso al elemento en que vivía... El lobo marino es semejante a un gran cachorro, con la precisa diversidad en pies y manos: tan voraz y destrozador de peces menores como el lobo terrestre de ganado: es de ferocidad rara que muestra al defenderse de hombres armados de acero y en las peleas porfiadas y sangrientas que mantiene con los machos de su especie por defender las hembras” (pp. 33-34).

Juan Ignacio Molina (1987), en Ensayo sobre la Historia Natural de Chile, contribuyó con referencias sobre las características físicas y costumbres alimentarias de diversas especies de lobos marinos que, según sus observaciones y antecedentes recopilados en Europa, habitan desde el archipiélago de Juan Fernández hasta el Estrecho de Magallanes. Además, el abate describió las técnicas de pesca y caza que utilizaban los loberos y las actividades económicas derivadas del uso de los productos obtenidos de su faenamiento:

"Los chilenos matan anualmente gran cantidad, procurando golpearlos con un bastón en la nariz, que es la parte más sensible que tienen. Su piel sirve para varios usos, pero especialmente para formar una especie de balsas... Las mismas pieles, bien curtidas, adquieren una textura similar a la del marroquí y si no son tan finas como éste, tienen sin embargo mayor consistencia y no se despellejan tan fácilmente. Con ellas se confeccionan buenos zapatos y calzado resistente al agua, cuando son bien cosidas. Los campesinos también se hacen vestidos con el pelo vuelto hacia afuera... En Londres se hace con ese pelo un paño sumamente mullido y más suave al tacto que el mismo 
terciopelo. Los ingleses se procuran estas pieles en Nueva Zelandia, islas situadas frente a Chile, donde los lobos marinos, o sea, los uriñes se propagan también en gran cantidad... Los chonos, habitantes del archipiélago de Chiloé, extraen de la grasa de estos animales un buen aceite, que llevan a vender a la ciudad. Este aceite, bien refinado, es óptimo para curtir y también para quemar y como se conserva siempre claro, es preferido para estos objetos al de ballena" (pp. 267-275).

Por su parte, José Pérez de García (1900), en Historia natural, militar, civil y sagrada del Reino de Chile, aportó con tres menciones sobre estos mamíferos marinos, la primera, refiere a la existencia de ellos en los mares y costas de Chile, la segunda, sobre su abundancia en el archipiélago de Juan Fernández y, la tercera, que los aborígenes los utilizan con regularidad para alimentarse y construir balsas con sus pieles.

El francés Claudio Gay (1847) en el tomo I de su Historia física y política de Chile, que refiere sobre aspectos zoológicos, identificó seis especies de lobos marinos que, según sus antecedentes, se concentraban fundamentalmente en la zona austral del país. No obstante, justificó que no puede profundizar en la descripción de ellas porque aún existe mucho desconocimiento científico:

"La gran dificultad de proporcionarnos focas nos ha impedido estudiarlas con el cuidado que hemos empleado en los otros ramos de historia natural; así miramos nuestro trabajo como momentáneo, y útil sólo para llamar la atención de los viajeros. Nos limitamos a indicar más bien que describir las especies, que merecen ser mejor estudiadas, lo cual no se conseguirá hasta que los zoólogos del país hayan podido verlas y describirlas, llegando a desenmarañar el caos que existe en este gran orden, cuyas numerosas especies se hallan en general relegadas en las frías regiones de los dos hemisferios; además, sus investigaciones serían de la mayor utilidad, pues harían conocer mejor los animales que han llegado a ser después de algún tiempo el objeto de grandes expediciones marítimas" (pp. 72-73).

Además, sobre la explotación y el uso de los productos derivados de los lobos marinos, opinó que: "La caza ofrece en efecto grandes ventajas a los especuladores, proporcionándoles pieles y cubiertas en muy grande cantidad. En otro tiempo abundaban mucho en el Estrecho de Magallanes, y se extendían hasta la isla de Juan Fernández y aún más arriba; pero la caza continuada que ha sido hecha, sobre todo por los americanos del norte, las ha disminuido considerablemente, y las ha obligado a refugiarse en los lugares más ocultos de los archipiélagos y golfos; sin embargo, en Chiloé y la isla de la Mocha matan aún muchas, y todo el aceite que se consume en el alumbrado del interior de estas islas y en gran parte de Chile proviene de ellas" (p. 73).

Desde la segunda mitad del siglo XIX, la caza y pesca de lobos marinos se convirtió en un tema de constante preocupación para las autoridades y hombres de ciencia chilenos por la 
inexistencia de instituciones y normas que regularan su explotación. Esta situación, propicio un escenario de impunidad que fue aprovechado por embarcaciones nacionales y extranjeras que explotaron y comercializaron indiscriminadamente el recurso (Vera, 1897; Martinic, 1973).

Durante esta época, la llegada a Chile del alemán Rodolfo Philippi, a la postre director del Museo de Historia Natural de Santiago y académico de la Universidad de Chile, significó un gran avance para el conocimiento de los lobos marinos y, además, en los primeros intentos por lograr una regulación sobre su explotación (Berguño, 1993).

En 1860, Philippi, invitado a visitar la isla de Juan Fernández por José Tomás de Urmeneta, obtuvo un cráneo y cuero de uno de ellos que, en 1864, envío al Dr. Wilhelm Peters, naturalista y director del Museo de Berlín para ser investigados. Los resultados del estudio fueron difundidos por el propio Peters en la clase de ciencias físicas y matemáticas de la Academia de Ciencias de Berlín, el 19 de marzo de 1866, donde señaló que la especie no había sido descrita con anterioridad y, por tanto, en honor a su descubridor sería llamada como "Otaria Phillipi". Con posterioridad, un extracto de la conferencia de Peters se publicó en Anales de la Universidad de Chile de 1867 (Philippi, 1867a; Sanhueza y Valderrama, 2016). Se debe destacar que Philippi en esa misma revista dio a conocer un trabajo donde criticó a Juan Molina y Claudio Gay por las deficientes descripciones y múltiples errores sobre los lobos marinos, especialmente, en lo referente a su fisiología, alimentación y ubicación geográfica (Philippi, 1867b).

A inicios de la década de 1880, la pesca y caza de lobos marinos iba en considerable aumento, situación que se debió, al parecer, a las regulaciones que Estados Unidos y Rusia comenzaron a aplicar sobre esta industria en la región de Alaska, a través del otorgamiento de arriendos y concesiones a particulares, provocando que muchos loberos que frecuentaban esas zonas vieran ahora en los mares y costas del sur una alternativa para seguir libre e impunemente con su explotación. Este nuevo escenario, fue denunciado en 1880 por el gobernador del Territorio de Magallanes, Francisco Sampaio Guzmán, quien solicitó al gobierno la prohibición de la pesca y caza de lobos marinos hasta que se estableciera una reglamentación que impusiera contribuciones sobre aquellos que realizaban la actividad (Vera, 1897; Martinic, 1973).

En 1880, Benjamín Vicuña Mackenna (1880) publicó La Patagonia, estudio geográfico y político dirigido a esclarecer el litigio chileno-argentino por la zona austral, donde señaló que la abundancia de lobos marinos en los sectores cercanos al archipiélago de las Guaitecas y en la Patagonia, permitiría establecer empresas industriales capaces de mantener a una gran cantidad de población que podría fortalecer la soberanía nacional y "viviría principalmente de la pesca de lobos que es abundantísima y de la explotación de su guano" (p. 213).

Un año después, Vicuña Mackenna (1939), en su calidad de senador, llamó la atención en la Sesión 17 Extraordinaria del 18 de diciembre de 1882, sobre la necesidad de una reglamentación de la pesca de lobos en Magallanes:

“Antes de pasar a otra partida me permito usar de la palabra para una cuestión de mucha importancia, relativa a la colonia de Magallanes, y es la reglamentación de 
la pesca de lobos. Es una riqueza extraordinariamente notable que tiene allí el país y en el actual sistema se hace tal destrucción, que llegará a desaparecer la industria. Se me ha dicho que un simple marino con la pesca de lobos ha hecho una fortuna de 200.000 pesos, de los cuales 100.000 los ganó en un solo año. Pero pesca en toda época, porque no hay ninguna regla establecida. El mismo Gobernador de Magallanes me escribió hace un año o más, sobre la necesidad de esta reglamentación. Hace poco tiempo leía en un diario muy serio de Inglaterra, La Revista del Sábado, el hecho de que el año 1800 había llegado un buque con un cargamento de un millón de cueros de lobos, de Magallanes, el cargamento más rico que las compañías comerciales habían enviado hasta entonces a Inglaterra, pues valía 7.000.000 de pesos y que hoy valdría 40.000.000. Esa misma riqueza fue causa de que se agotara ese comercio y de que se perdieran esos millones para el país. Yo me permito rogar al señor Ministro que reglamente ese ramo" (pp. 472-473).

Además, Vicuña Mackenna, en su trabajo Juan Fernández. Historia verdadera de la isla de Robinson Crusoe, publicado en 1883, realizó una completa descripción de la historia y geografía del archipiélago y expuso en varios capítulos abundantes antecedentes sobre los lobos marinos que habitaban sus costas, detallando aspectos morfológicos y anatómicos y las costumbres que tenían en tierra y mar. También, dedicó especial atención a los antecedentes documentales existentes -hasta esa época- sobre avistamientos de embarcaciones extranjeras que cazaban clandestinamente a estos mamíferos en aguas chilenas, argentinas y peruanas y sobre las correspondientes denuncias realizadas por las autoridades de la isla para poner fin a su indiscriminada explotación en el Pacífico Sur (Vicuña, 1883).

Igualmente, describió las estrategias y armas utilizadas para pescar y cazar a los lobos marinos y las técnicas para faenar la carne, proteger las pieles y producir el aceite, además de mencionar los valores que estos productos alcanzaban en los mercados europeos, norteamericanos y asiáticos donde eran usados para la fabricación de cordonerías, sillas de montar, sombreros, entre otros. No obstante, juzgó que "por la falta de una reglamentación adecuada, era un negocio que languidecía y agonizaba en los mares y costas de Chile, especialmente en Juan Fernández y Magallanes, siendo necesario seguir el ejemplo de la República Argentina que trató de organizarlo por medio de privilegios" (Vicuña, 1883, p. 237).

Coincidentemente con la última publicación de Vicuña Mackenna, el 16 marzo de 1883, el canciller Luis Aldunate Carrera convocó a Oscar Viel, Alfredo von Rodt y H. A. Honland para formar una comisión con el objetivo de estudiar este problema y proponer un proyecto de reglamento. Lamentablemente la comisión fracasó por las dificultades que tuvieron los integrantes para reunirse, continuando libre e indiscriminadamente la explotación de los lobos marinos (Martinic, 1973; Berguño, 1993; Mancilla, 2010).

En 1889, Philippi, una vez más volvió sobre el tema de los lobos marinos en su trabajo "Rectificación de algunos errores con respecto a las focas o lobos de mar de Chile", publicado 
en Anales de la Universidad de Chile, donde defendiendo sus estudios y aquellos realizados en Alemania por el Dr. Peters, denunció los errores que existían en las obras de los naturalistas Hermann Burmeister (1879), director del Museo Público de Buenos Aires, y Eberhard A. Wilhelm von Zimmermann (1883), profesor de la Universidad de Brunswick, quienes habrían confundido a los lobos marinos que habitaban en las costas y mares de Chile, especialmente en el archipiélago de Juan Fernández y el Territorio de Magallanes, con otras avistadas en latitudes muy distantes al país (Philippi, 1889).

Durante los años siguientes, los Ministerios de Relaciones Exteriores e Industria y Obras Públicas, más los gobernadores del Territorio de Magallanes, principalmente Daniel Briceño y Manuel Señoret, alertados por el casi exterminio de los lobos marinos por la explotación clandestina que realizaban embarcaciones de distintas nacionalidades y, además, por las informaciones llegadas a la cancillería sobre las concesiones otorgadas por el gobierno argentino para explotar los recursos naturales en el Atlántico Sur (Berguño, 1999), conllevaron a la decisión del presidente Jorge Montt de encomendar, en los inicios de 1892, a Rodolfo Philippi para continuar con los estudios iniciados por la comisión de 1883 para reglamentar esta actividad (Chaigneaux, 1898; Jara, 2012).

Los resultados alcanzados por Philippi fueron, ese mismo año, publicados por orden el gobierno en Anales del Museo Nacional de Chile con el título de "Las focas chilenas del Museo Nacional: figuras y descritas", donde el director del Museo expuso sobre los últimos avances en el conocimiento sobre los lobos marinos, centrándose fundamentalmente en la descripción y comparación entre los lobos de uno y dos pelos a través de una serie de láminas evidenciaban sus diferencias fisiológicas y morfológicas y los peligros que significaba para ambas su indiscriminada pesca y caza (Philippi, 1892).

Meses después de la publicación de Philippi, puntualmente el 17 de agosto de 1892, el Ministerio de Industrias y Obras Públicas decretó la Ordenanza de Pesca No 1.623 que, con el acuerdo del Consejo de Estado, prohibió absolutamente durante los meses de noviembre, diciembre, enero y febrero de cada año la caza o pesca de focas o lobos marinos, nutrias y chungungos en las costas, islas y mares territoriales de Chile (Romero, 1985). No obstante, tres días después, se dictó el Decreto No 1.642 que prohibió por un año la caza y pesca en las Gobernaciones Marítimas de Chiloé y Magallanes y en las costas del archipiélago de Juan Fernández y, posteriormente, el 19 de agosto de 1893, se extendió por cuatro años más a través del Decreto $\mathrm{N}^{\circ} 83$.

"LOS LOBOS MARINOS DE CHILE” Y “LOS PINÍPEDOS DE CHILE”: APORTES A LA DISCUSIÓN SOBRE LOS BENEFICIOS Y/O PERJUICIOS DE LA ORDENANZA DE PESCA DE 1892

Federico Albert, apenas llegó a Chile en 1889, inmediatamente comenzó sus labores en el Museo de Historia Natural de Santiago y, a fines de 1898, se trasladó al Ministerio de Industria y Obras Públicas para asumir, desde 1900, la dirección de la Sección de Ensayos 
Zoológicos y Botánicos, instancia donde destacó por sus trabajos científicos y constantes propuestas para elaborar nuevas y/o modificar las existentes legislaciones que resguardaban los recursos naturales del país (Albert, 1902, 1906b).

Es así, que en las siguientes páginas, analizaremos los aportes de Albert a la discusión sobre los beneficios y perjuicios de la Ordenanza de Pesca $N^{0} 1.642$, que reguló la pesca y caza de lobos marinos en los mares y costas nacionales entre 1892 y 1904, a través de dos escritos de su autoría, a saber, "Los lobos marinos de Chile" y "Los pinípedos de Chile", publicados en 1901 en la Revista Chilena de Historia Natural del Museo de Historia Natural de Valparaíso y Anales de la Universidad de Chile, respectivamente, y que -en palabras de Albert- "fueron elaborados gracias a las recopilaciones de sus viajes de exploración y datos que obtuvo de informes que solicitó a las autoridades administrativas, empresarios, hombres de ciencia y profesores que desarrollaban sus actividades en distintas zonas del territorio nacional" (p. 879).

Es importante destacar que estos trabajos de Federico Albert -al igual aquellos de Philippi que sustentaron la dictación de Ordenanza de Pesca de 1892-, sumados a los importantes e influyentes informes que sobre el asunto envío a las autoridades en su función de director de la Sección de Ensayos Zoológicos y Botánicos, fueron utilizados con posterioridad para modificar en 1903 y, en 1904, derogar la Ordenanza.

"Los lobos marinos de Chile", es un texto de 9 carillas y dividido en dos secciones. La primera, Albert la dedicó a señalar los contrastes entre los lobos marinos y las focas y ubicarlos geográficamente y, la segunda, se preocupó de explicar las diferencias entre los lobos de un pelo y los de dos pelos.

Es así, que sobre el primer punto, Albert sostuvo que los lobos marinos se dividen en dos familias, las Phocidae o focas y los Otariidae o lobos, señalando que las focas se distinguen fácilmente de los lobos porque no tienen orejas exteriores y sus extremidades son débiles y, además, porque habitan en los océanos Ártico y Atlántico y en los mares Mediterráneo, Negro y Caspio y en los lagos Aral y Baikal, siendo el elefante de mar la única especie de esta familia que se avista en los mares y costas de Chile. No obstante, refirió que, posiblemente, en siglos pasados, fueron muy común entre California y Magallanes (Albert, 1901a).

Posteriormente dividió a los lobos marinos en dos géneros: Otaria o lobo de un pelo y Callorhinus o lobos de dos pelos, que se caracterizan morfológicamente por poseer orejas exteriores, extremidades largas y robustas y habitar en las regiones templadas y frías del hemisferio norte del océano Pacífico, Colonia del Cabo, Australia, Nueva Zelanda y las costas de América del Sur. En esta última zona, a su vez, los lobos de un pelo se distribuyen entre las costas de Perú y las islas Falkland y que, en el caso puntual de Chile, estos se concentran en las loberías de las provincias del Maule (Punta Carranza), Colchagua (Punta Lobos y Topocalma), Aconcagua (Los Molles, Pichidangui, Punta de Lobos) y Coquimbo (Teniente Bay, Piedra de Lobos). Por su parte, los lobos de dos pelos se agrupaban en las islas de San Félix, San 
Ambrosio y Más Afuera y en las provincias de Chiloé y Llanquihue, el Territorio de Magallanes, Tierra del Fuego, las islas Falkland y las áreas antárticas (Albert, 1901a).

En la segunda sección, Albert abordó las diferencias fisiológicas entre machos y hembras en ambos tipos de lobos marinos, agregando informaciones relacionadas con sus costumbres de procreación y alimentación para, posteriormente, referirse sobre los peligros de crear sistemas de protección para los lobos de un pelo, principalmente por su voracidad y pocos beneficios económicos, a diferencia de los lobos de dos pelos. Estos últimos, por la calidad de sus pieles y aceites, creía necesario resguardarlos especialmente en las costas de Juan Fernández, Chiloé y Magallanes, donde era difícil mantener un control sobre la indiscriminada explotación, siendo prudente modificar la Ordenanza de Pesca de 1892 (Albert, 1901a).

El segundo texto, “Los pinípedos de Chile”, tiene una extensión de 58 carillas separadas en cuatro apartados. En el primero, Albert, plantea sus motivaciones para la elaboración del trabajo, la segunda, refiere a las diferencias entre lobos marinos y focas, la tercera, sobre los beneficios y perjuicios económicos de los lobos de uno y dos pelos y, por último, realiza una serie de críticas a la Ordenanza de Pesca y plantea algunas soluciones sobre el asunto.

Sobre el primer apartado, Albert explicó que esta investigación tiene su génesis en los estudios que realizó durante su estadía en el Museo de Historia Natural de Santiago y que, posteriormente, complementó con nuevas informaciones que obtuvo al asumir la dirección de la Sección de Ensayos Zoológicos y Botánicos del Ministerio de Industria y Obras Públicas. Siendo en esta última instancia donde evidenció la necesidad de perfeccionarlos a fin de sustentar posibles modificaciones o, simplemente, la derogación de la Ordenanza de 1892 (Albert, 1901b).

Con respecto a los antecedentes usados para la elaboración del trabajo, Albert señaló que este se efectuó con 34 viajes a distintas loberías del país y donde pudo comprobar los verdaderos alcances de la indiscriminada caza y pesca de lobos marinos y, en segundo lugar, en base a los informes que solicitó a diferentes autoridades regionales, empresarios loberos de las islas de Juan Fernández y Chiloé y personalidades científicas del Territorio de Magallanes y Tierra del Fuego. Por último, sobre la nomenclatura, explicó que se encontraba basada en la elaborada por el zoólogo francés Édouard Louis Trouessart (1897 y 1899) y complementadas con los "sinónimos correspondientes a las nuevas especies descritas con posterioridad a esta obra” (Albert, 1901b, p. 880).

En el segundo apartado, Albert se dedicó a describir con detalle a las Phocidae y Otariidae, subdividiéndolas en varios géneros que, dependiendo de sus características, habitan en los mares y costas del mundo. Sobre las primeras, señaló que las únicas que se observaban con frecuencia en las zonas centro-sur, australes y antárticas chilenas eran las denominadas Macrorhinus Leoninus y Leptonychotes Weddellii, mientras que, de las Otariidae, solamente las Otarias Flavescens (lobo de un pelo) y Arctocephalus (lobo de dos pelos o lobo fino). No obstante, con respecto a estos últimos -lobo de dos pelos- él 
creí que ya se habían extinguido por completo en las costas entre Atacama y Chiloé y, además, en las islas de San Félix, San Ambrosio y Pascua, por tanto, era necesario dejar a las expediciones a las islas antárticas de propiedad nacional la confirmación de su posible existencia (Albert, 1901b).

A continuación, abunda en explicaciones comparativas entre los lobos de uno y de dos pelos, centrándose en elementos fisiológicos y morfológicos, comportamientos migratorios, reproductivos y alimentarios y los impactos que las actividades humanas tenían sobre cada uno de ellos.

En la tercera parte del texto, el autor analizó los beneficios y perjuicios económicos generados por la explotación de los lobos de uno y dos pelos, donde fue tajante al decir que los primeros "traen insignificantes aportes monetarios al erario nacional y, por ende, no era conveniente protegerlos, sino que, por el contrario, era recomendable su extinción” (Albert, 1901: 1.038). Para esto último, juzgó necesario estudiar las reglamentaciones existentes en Estados Unidos, Inglaterra, Dinamarca, Suecia, entre otros, donde se pagaban elevadas sumas de dinero por cada cabeza de este animal, ${ }^{2}$ mientras que en Chile eran protegidos con normativas que imponían severas multas a quienes los cazaban dentro de los límites jurisdiccionales del país (Albert, 1901b).

Sobre los lobos de dos pelos, Albert consideraba que su número era muy difícil de calcular, sin embargo, según las informaciones que había obtenido de varios informes de autoridades locales, pensaba que en Juan Fernández estos podían llegar a ser entre cinco a seis mil individuos, número que sería mayor en la región magallánica, islas al sur de Tierra del Fuego y en la Antártica, lugares donde "se alimentaban de peces que iban desde el tamaño de una sardina hasta grandes robalos, congrios y pulpos, consumiendo prácticamente su propio peso en alimento. Esto último, significaba un gran perjuicio para la pesca nacional, no obstante, por el alto valor de sus pieles y aceite en los mercados estadounidenses y europeos era conveniente regular su explotación” (Albert, 1901b, p. 894 y p. 902).

En este mismo apartado, Albert abordó las técnicas y armas utilizadas para capturar y matar a los lobos de dos pelos, señalando que, según sus observaciones: "los loberos generalmente se reunían en grupos de cuatro a veinte y armados con lazos, escopetas y macanas, se acercaban sigilosamente en botes o balsas a los islotes y/o costas donde se situaban los lobos y cuidando siempre de ir por el lado opuesto al viento para así evitar que estos -los lobos- se arrojaran al mar... una vez en tierra, los loberos se precipitaban con sus aparatos preferentemente sobre la nariz o la cabeza de los lobos, dando muerte a varios individuos y sin discriminar entre machos y hembras... una vez muertos, se extraían sus pieles y aceite” (Albert, 1901b. pp. 1.017-1.018).

2 En Estados Unidos pagan por un lobo de un pelo hasta un Dólar, Inglaterra una Libra, Dinamarca 10 Coronas, Suecia hasta 10 Coronas. Dinamarca gastó en primas desde 1891 hasta 1897 la suma de 29.865 Coronas, en Suecia en 1898 se gastaron alrededor de 15.000 Coronas fuera de los fusiles de sistema antiguo que han repartido a los pescadores a fin de que se dediquen a la caza de los lobos de un pelo. 
Del mismo modo, explicó el procedimiento y las atenciones que se debían considerar para la extracción, lavado, secado y conservación de las pieles. Sobre esto último, escribió que "los loberos las extendían y apilaban unas sobre otras, pelo con pelo y grasa con grasa, y las dividían con una capa de sal de aproximadamente un centímetro" (Albert, 1901b, p. 899). Mientras que, sobre la venta de las pieles, estas tenían en valor reducido e incluso nulo en los mercados nacionales en comparación con los alcanzados en Argentina, Estados Unidos o Europa (Albert, 1901b, p. 901), no obstante, pensó que la industria de los lobos de dos pelos debía ser considerada por el Estado como la más útil y provechosa y, por lo mismo, era necesario e indispensable tratar de no extinguirla y conservarla a través de una explotación prudente.

En el último apartado de "Los pinnípedos de Chile", Albert expuso cuatro críticas a la implementación de las regulaciones articuladas en la Ordenanza de Pesca. La primera, es el insuficiente resguardo que las autoridades tenían sobre las loberías en algunos meses del año, principalmente entre noviembre a febrero, era el período de más peligro y en el cual los explotadores de maderas, pequeños negociantes con embarcaciones de poco calado, pescadores y cazadores de las inmediaciones, aprovechaban para matar indiscriminadamente a los lobos marinos (Albert, 1901b).

La segunda, que las Comandancias Generales de Marina, pasando por alto la prohibición absoluta, otorgaban a empresas permisos -encubriéndolos bajo otros giros productivos- para pescar y cazar a los lobos marinos. Sin embargo, seguía siendo más recurrente y peligrosa la clandestinidad, especialmente porque los loberos para evitar sanciones preferían no atracar en los puertos nacionales o, simplemente, hacer traspasos de las pieles y aceites a otras embarcaciones que pasaban por esas regiones (Albert, 1901b).

La tercera, referida a que la prohibición de la pesca y caza no debía provenir de una simple ordenanza administrativa, sino que, por el contrario, de disposiciones jurídicas emanadas de los legisladores, otorgando facultades a las autoridades para sancionar con pena de prisión y decomiso efectivo de especies y embarcaciones a quienes no las respetaran. Situación que no se da con la Ordenanza de 1892, que solamente limitaba a la autoridad a sancionar con multas monetarias su no cumplimiento (Albert, 1901b).

Por último, que en la Ordenanza no se distinguían entre animales útiles y perjudiciales. En tal sentido, juntar bajo una misma regulación a los lobos de uno y dos pelos era un grave error. Principalmente, porque los primeros no proporcionaban ningún beneficio a la economía nacional (Albert, 1901b).

Junto a las críticas presentadas, Albert también planteó posibles soluciones.

En primer lugar, el ejemplo de Estados Unidos y Rusia era el más recomendable a seguir. Estos dos países luego de haber estado afectados por los mismos inconvenientes durante muchos años y darse cuenta de la ineficacia de los reglamentos, leyes y prohibiciones, llegaron a la conclusión que lo mejor era ofrecer en arriendo la pesca y caza, entregando el 
monopolio de la explotación y resguardo de los lobos marinos a una sola empresa fuertemente fiscalizada (Albert, 1901b) .

En segundo lugar, considerando que las loberías estaban muy esparcidas y eran de difícil vigilancia para el Estado, era más beneficioso entregar en arriendo la caza de lobos finos a grandes sociedades mediante una subasta pública. Las que deberían cumplir con una fianza correspondiente a los posibles perjuicios que pudieran causar, atenerse estrictamente a la Ordenanza de 1892, ejercer la vigilancia en la época de la veda, pagar un arriendo anual, semestral o trimestral de una suma determinada y una cantidad adicional por cada cuero obtenido. Además, los contratos tendrían una vigencia de diez o veinte años, a fin de que las mismas sociedades pudieran conservar las especies y aumentaran su productividad (Albert, 1901b).

En tercer lugar, en las Gobernaciones Marítimas debía crearse y mantenerse actualizado un registro de los nacionales y extranjeros domiciliados en el país que estaban dedicados a la pesca y caza de lobos marinos y de estos nombrarse los guarda-pescas encargados de vigilar los sectores y aplicar las disposiciones que se consignaban en la Ordenanza. Además, cobrar el derecho de un peso cincuenta centavos por cada piel de lobo cazado para que el Estado pudiera obtener una renta y cubriera los gastos que demandaba la vigilancia de las loberías (Albert, 1901b).

En cuarto lugar, liberar la caza de los lobos de un pelo que estaban siendo protegidos por la Ordenanza de Pesca y comenzar a pagar primas en moneda corriente o en pólvora y municiones por la entrega de sus cabezas. Simultáneamente, aprovechar la abundancia de los lobos de un pelo e instalar industrias dedicadas a la producción de aceite de lobo, utilización de la piel curtida con o sin pelos para la elaboración de lazos y correas o forro de baúles, maletas, sillas, sillas de montar, entre otros y, finalmente, el uso de los colmillos para trabajos en marfil, mangos de bastones, paraguas, quitasoles, puñales, cuchillos, entre otros (Albert, 1901b).

La última propuesta de Albert fue que el Estado debía destinar recursos económicos y materiales a los departamentos ministeriales para que estos informaran a través de publicaciones en diarios, revistas y en conferencias públicas en todo el país, las consecuencias de la sobreexplotación y el exterminio de los lobos de dos pelos, con el objeto de favorecer su conservación frente a los perjuicios que provocaban los lobos de un pelo. No obstante, si esto no se lograba, había que dar las facilidades reglamentarias para la formación de sociedades particulares de caza y de protección de los animales marinos, con el fin de que fueran estas las encargadas de publicitar las propagandas en beneficio de las especies útiles, de velar por el estricto cumplimiento de los reglamentos y, en lo posible, proponer sus modificaciones (Albert, 1901b).

Estas mismas empresas, se comprometían, asimismo, a cumplir con otras disposiciones, tales como la prohibición de ensuciar las vecindades de las loberías; escupir, fumar o mascar tabaco; derretir la grasa o hacer fuego en las inmediaciones de las loberías; llevar a las loberías a niños y mujeres; prohibir el uso de armas de fuego y, finalmente, mantener los perros a distancias superiores a 3,5 kilómetros de los lugares donde habitaban o se instalaban los lobos marinos. 


\section{CONCLUSIONES}

El tema de la explotación de los lobos marinos se encuentra presente en la literatura de circulación nacional desde el período colonial. Máxime, será desde mediados del siglo XIX que, frente al aumento de las denuncias sobre la indiscriminada caza y pesca de lobos y otros problemas vinculados al diferendo limítrofe con Argentina, las autoridades nacionales y del Territorio de Magallanes abordarán el asunto en su real dimensión y sustentándose en apreciaciones científicas, dictarán reglamentaciones y otras disposiciones legales para regular esta actividad, principalmente, en el archipiélago de Juan Fernández, Chiloé y Magallanes.

En la búsqueda por definir una reglamentación, el gobierno chileno nombró una primera comisión en 1883 que no logró su objetivo. Sin embargo, algunos años después el presidente Jorge Montt encargó a Rodolfo Philippi retomar el trabajo solicitado en 1883 y elaborar una propuesta para la dictación de una Ordenanza de Pesca. Hecho que, al cabo de pocos meses, se concretó y el 17 de agosto de 1892 el país pudo contar con una primera normativa sobre estas materias.

Por esa misma fecha llegaba al país el naturalista germano Federico Albert, a trabajar al Museo de Historia Natural y, desde inicios del siglo XX, al Ministerio de Industria y Obras Públicas. En ambas instituciones, Albert mostró preocupación por los lobos marinos, al punto de publicar dos importantes estudios "Los lobos marinos de Chile" y "Los pinnípedos de Chile", cuya difusión se realizó en la Revista Chilena de Historia Natural del Museo de Historia Natural de Valparaíso y en Anales de la Universidad de Chile en 1901. En estas publicaciones, Albert estableció las siguientes ideas: 1) los últimos avances científicos sobre estos animales marinos establecían la diferencia entre los lobos de un pelo y dos pelos, 2) las técnicas y armas utilizadas por los loberos para capturar y aniquilar a sus víctimas y obtener sus pieles y aceites y, 3) críticas a la Ordenanza de Pesca y posibles alternativas para tener una reglamentación que permitiera sustentar esta actividad en el tiempo.

Finalmente, destacar que estos trabajos de Albert habrían sido fundamentales para modificar y derogar en 1903 la Ordenanza de Pesca de 1892 y redefinir la política chilena de protección de estos animales marinos, especialmente, en los territorios de Magallanes, Tierra del Fuego y mares e islas más australes y con proyección al continente antártico.

\section{REFERENCIAS}

Albert, F. (1898a). La langosta de Juan Fernández y la posibilidad de su propagación en la costa chilena. Revista Chilena de Historia Natural, 2, 5-11.

Albert, F. (1898b). Contribución al estudio de las aves chilenas. Anales de la Universidad de Chile, 579-591.

Albert, F. (1900). Las dunas, o sean las arenas volantes, voladeros, arenas muertas, invasión de las arenas, playas i médanos del Centro de Chile. Anales de la Universidad de Chile, 
107, 643-653.

Albert, F. (1901a). Los lobos marinos de Chile. Revista Chilena de Historia Natural, 5(2), 33-41. Albert, F. (1901b). Los pinípedos de Chile. Anales de la Universidad de Chile, 108-109(59), 879-903, 1007-1039.

Albert, F. (1902). La caza en el país. Santiago: Sin imprenta.

Albert, F. (1906a). La replantación de los cerros áridos del país. Santiago: Imprenta Moderna.

Albert, F. (1906b). Los servicios de agua y bosques. Santiago: Imprenta Barcelona.

Albert, F. (1907). Plan general para el cultivo de bosques. Santiago: Imprenta Cervantes.

Albert, F. (1909). Los 7 árboles forestales más recomendables para el país. Santiago: Imprenta Cervantes.

Albert, F. (1910). La organización que se debe dar en lo futuro a los Servicios de Aguas y Bosques de acuerdo con los estudios hechos en Europa. Santiago: Imprenta Cervantes.

Albert, F. (1911). La necesidad urgente de crear una Inspección General de Bosques, Pesca y Caza. Santiago: Imprenta Cervantes.

Albert, F. (1913). El problema pesquero en Chile. Santiago: Imprenta Kosmos.

Albert, F. (1924). Informaciones para establecer un intercambio comercial y fomentar la implantación de industrias y empresas nacionales. Santiago: Imprenta Universo.

Allen, J. A. (1870). On the eared seals (Otariadae), with detailed descriptions of the North Pacific species. Bulletin of the Museum of Comparative Zoology, 2, 1-89.

Berguño, J. (1993). Las Shetland del Sur: El ciclo lobero. I Parte. Boletín Antártico Chileno, 12(1), 5-13.

Berguño, J. (1999). El despertar de la conciencia antártica (1874-1914): los orígenes del litigio internacional. Boletín Antártico Chileno, 18(2), 2-21.

Burmeister, H. (1879). Descripción física de la república Argentina Tomo III. París: Imprimerie de Paul-Émile Coni.

Camus, P. (2003). Federico Albert: artífice de la gestión de los bosques de Chile. Revista de Geografía Norte Grande, 30, 55-63.

Chaigneaux, F. (1898). La pesca ante el porvenir de la Marina de Guerra. Revista de Marina, XXV(150), 2194-2196.

Clark, J. W. (1878). Notes on three stuffed specimens of the sea-lion of the pribilov Islands (Otaria ursine). Proceedings of the Zoological Society of London, 371-373.

Gay, C. (1847). Historia física y política de Chile. Zoología Tomo I. París: Imprenta de Maulde y Renou.

Gray, J. E. (1863). The ringed seal (Phoca foetida). Annals and Magazine of Natural History, 11(64), 309.

Gray, J. E. (1866). Notes on the skulls of sea-bears and sea-lions (Otariadae) in the British Museum. Annals and Magazine of Natural History, 18(105), 228-237.

Gray, J. E. (1868). Observations on sea-bear (Otariadae), and especially on the fur-seals and hair-seals of the Falkland Island and Southern America. Annals and Magazine of Natural 
History, 1, 99-110.

Gray, J. E. (1874). On the skulls of sea-bears and sea-lions (Otariadae), and on the seals of the Auckland Islands. Annals and Magazine of Natural History, 14, 24-30.

Jara, M. (2012). Las “islas australes” y los prolegómenos de la política antártica chilena, 18921896. Estudios Hemisféricos y Polares, 3(4), 269-286.

Joly, M. (1858). On a new species of Haematozoon of the genus Filaria, observed in the heart of a Seal (Phoca vitulina, Linn). Annals and Magazine of Natural History, 1, 399-400.

Mancilla, P. (2010). La génesis del conocimiento científico chileno sobre los territorios australes-antárticos, 1820-1884. Estudios Hemisféricos y Polares, 1(1), 46-68.

Martinic, M. (1973). Actividad Lobera y Ballenera en Litorales y Aguas de Magallanes y Antártica, 1868-1916. Revista de Estudios del Pacífico, 7, 7-26.

Mayorga, M. (2016). Antecedentes históricos referidos a la caza de lobos marinos y su interacción con el medio geográfico y humano en el extremo austral americano: el caso del lobero escocés William Low. Magallania, 44(2), 37-64.

Medina, J. T. (1952). Cosas de la colonia. Apuntes para la crónica del siglo XVIII en Chile. Santiago: Imprenta Universitaria.

Molina, J. (1987). Ensayo sobre la historia natural de Chile. Santiago: Ediciones Maule.

Olivares, M. (1864). Historia militar, civil y sagrada de lo acaecido en la conquista y pacificación del Reino de Chile. En Colección de Historiadores de Chile y Documentos Relativos a la Historia Nacional Tomo IV. Santiago: Imprenta del Ferrocarril.

Pérez de García, J. (1900). Historia natural, militar, civil y sagrada del Reino de Chile. En Colección de Historiadores de Chile y Documentos Relativos a la Historia Nacional Tomo XXII. Santiago: Imprenta Elzeviriana.

Philippi, R. (1867a). Zoología. Sobre una nueva especie de foca o lobo marino del mar chileno, descrita por el profesor Peters. Anales de la Universidad de Chile, 29, 802-807.

Philippi, R. (1867b). Comentario crítico sobre los animales descritos por Molina. Anales de la Universidad de Chile, 29, 775-802.

Philippi, R. (1889). Rectificación de algunos errores con respecto a las focas o lobos de mar de Chile. Anales de la Universidad de Chile, 75, 60-64.

Philippi, R. (1892). Las focas chilenas del Museo Nacional: figuradas y descritas. Anales del Museo Nacional de Chile, 1, 1-75.

Romero, P. (1985). Síntesis de la Historia Antártica de Chile. Acompañada de documentos fundamentales. Santiago: Universidad de Santiago de Chile.

Rosales, D. (1877). Historia General de el Reino de Chile, Flandes Indiano. Valparaíso: Imprenta del Mercurio.

Sanhueza, C., \& Valderrama, L. (2016). Un lobo marino en controversia: materialidad, taxonomía y disputa científica (segunda mitad del siglo XIX). Historia, 49(2), 579-594.

Trouessart. É. L. (1897). Catalogus mammalium tam viventium quam fossilium Vol. I. ParisBerolini: R. Friedlander \& Sohn. 
Trouessart. É. L. (1899). Catalogus mammalium tam viventium quam fossilium Vol. II. ParisBerolini: R. Friedlander \& Sohn.

Vera, R. (1897). Magallanes i Tierra del Fuego, 1843 a 1897. Santiago: Imprenta de la Gaceta. Vicuña Mackenna, B. (1880). La Patagonia. Santiago: Imprenta del Centro Editorial.

Vicuña Mackenna, B. (1883). Juan Fernández. Historia verdadera de la isla de Robinson Crusoe. Santiago: Rafael Jover, Editor.

Vicuña Mackenna, B. (1939). Obras Completas. Discursos Parlamentarios Vol. III. Santiago: Universidad de Chile.

Walker, R. (1863). On the skeleton of a Seal (Phoca Groenlandia?), and the cranium of a duck, from the Pliocene beds, Fifeshire. Annals and Magazine of Natural History, 12, 382-388. Yáñez, J., \& Canto, J. (2013). Federico Albert, 1867-1928. Gestión Ambiental, 25, 1-9.

Zimmermann, E. (1883). Historia geográfica de los humanos y de los animales cuadrúpedos Volumen III. Alemania: Leipzig. 
